\title{
Serotonin and circadian rhythms
}

\author{
André Luiz Bezerra de Pontes $^{1}$, Rovena Clara Galvão Januário Engelberth ${ }^{1}$, Expedito da Silva \\ Nascimento, Jr. ${ }^{1}$, Judney Cley Cavalcante ${ }^{1}$, Miriam Stela Maris de Oliveira Costa ${ }^{1}$, Luciana \\ Pinato $^{2}$, Claudio Antonio Barbosa de Toledo ${ }^{3}$ and Jeferson de Souza Cavalcante ${ }^{1}$ \\ 1- Universidade Federal do Rio Grande do Norte, Natal, RN, Brazil. \\ 2- Universidade Estadual Paulista., Marília, SP, Brazil \\ 3- Universidade da Cidade de São Paulo, São Paulo, SP, Brazil
}

\begin{abstract}
All mammal behaviors and functions exhibit synchronization with environmental rhythms. This is accomplished through an internal mechanism that generates and modulates biological rhythms. The circadian timing system, responsible for this process, is formed by connected neural structures. Pathways receive and transmit environmental cues to the central oscillator, the hypothalamic suprachiasmatic nucleus, which mediates physiological and behavioral alterations. The suprachiasmatic nucleus has three major inputs: the retinohypothalamic tract (a direct projection from the retina), the geniculohypothalamic tract (an indirect photic projection originating in the intergeniculate leaflet), and a dense serotonergic plexus from the raphe nuclei. The serotonergic pathway, a source of non-photic cues to the suprachiasmatic nucleus, modulates its activity. The importance of raphe nuclei in circadian rhythms, especially in photic responses, has been demonstrated in many studies. Serotonin is the raphe neurotransmitter that triggers phase shifts, inhibits light-induced phase-shifts, and plays a role in controlling the sleep-wake cycle. All data to date have demonstrated the importance of the raphe, through serotonergic afferents, in adjusting circadian rhythms and must therefore be considered a component of the circadian timing system. The aim of this paper is to review the literature addressing the involvement of serotonin in the modulation of circadian rhythm. Keywords: raphe, circadian timing system, serotonin, circadian rhythm, suprachiasmatic nucleus.
\end{abstract}

Received 15 October 2010; received in revised form 20 November 2010; accepted 20 November 2010. Available on line 28 December 2010

\section{Biological rhythms}

Biological rhythms, which are endogenously generated, are sensitive to environmental information that allows live organisms to maintain a stable phase relationship with its environmental cycle, thereby adjusting the physiological variables needed for survival. When this relationship is established, the organism is considered synchronized to the environment (Marques, Golombeck, \& Moreno,

André Luiz Bezerra de Pontes, Rovena Clara Galvão Januário Engelberth,ExpeditodaSilvaNascimentoJr.,JudneyCleyCavalcante, Miriam Stela Maris de Oliveira Costa, Jeferson de Souza Cavalcante, Laboratory of Chronobiology, Biosciences Center, Universidade Federal do Rio Grande do Norte, Natal, Natal, RN 59072-970, Brazil. Luciana Pinato, Speech-Language and Hearing Therapy Department, Universidade do Estado de São Paulo, Marilia, SP 17525-900, Brazil. Claudio Antonio Barbosa de Toledo, Laboratory of Neurosciences, Neuroscience Research Nucleus, City University of São Paulo, São Paulo, SP 03071-000, Brazil. Correspondence regarding this article should be directed to: Jeferson S. Cavalcante, Department of Physiology, Biosciences Center, Federal University of Rio Grande do Norte, Natal, RN 59072-970, Brazil. Tel: +55-84 3215-3409. Fax: +55-84-3211-9206. E-mail: jefsc@uol.com.br
2003). The circadian rhythms are the most widely known and studied biological rhythms in terms of generation and modulation. They exhibit $24 \mathrm{~h}$ cycles and maintain stable phase relationships with the light/dark cycle, such as the sleep/wake cycle, locomotor activity rhythm, and the secretion rhythm of various hormones (Rotenberg, Marques, \& Menna-Barreto, 2003).

\section{Circadian timing system}

For an organism to establish an internal timing order, it must receive environmental information, process it, and send a response to such stimuli. These functions are performed by the circadian timing system (CTS), composed of a network of interconnected neural structures. The CTS is responsible for generating and modulating biological rhythms. The CTS of mammals has three main components: an afferent pathway (also called the primary synchronizing pathway, which receives information from the environment), a central clock responsible for generating circadian oscillations, and efferent pathways (through which the CTS communicates with behavioral and physiological effectors and through which the 


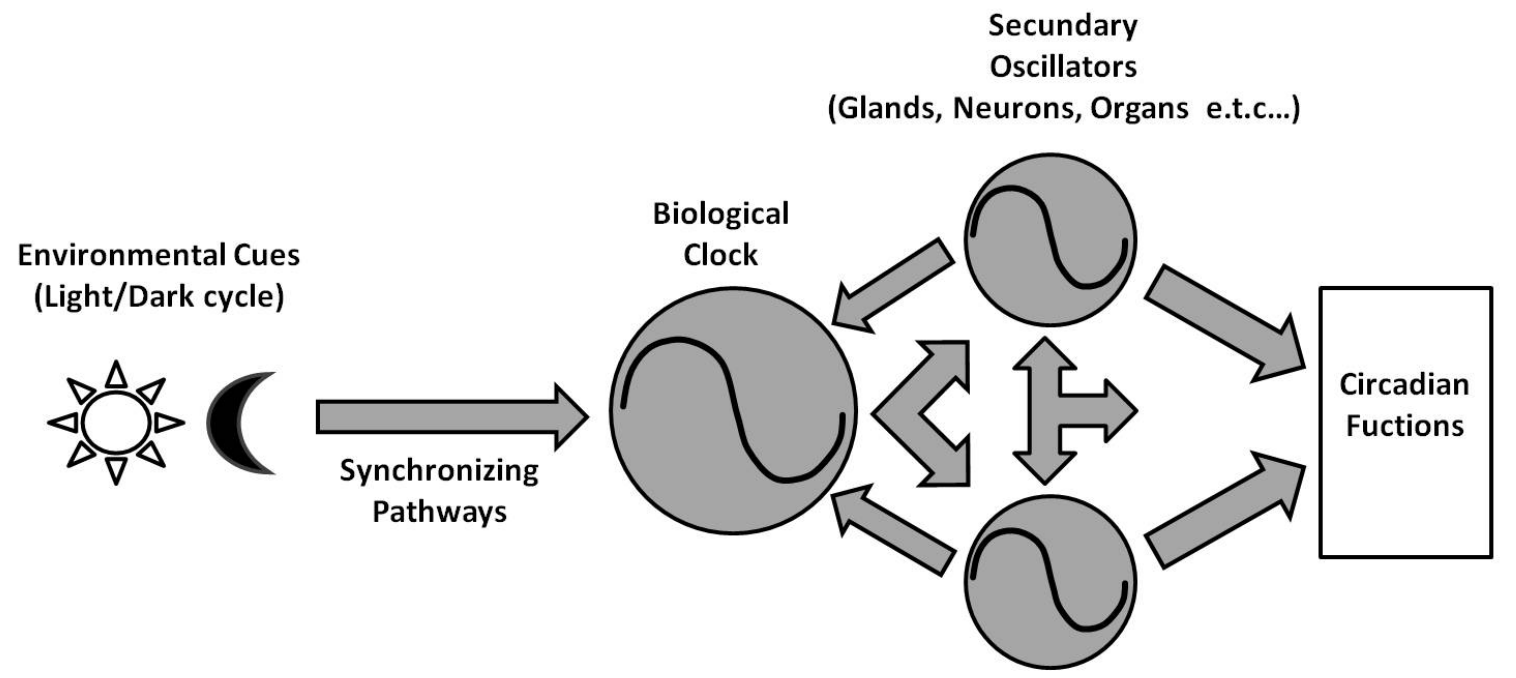

Figure 1. Illustrative schematic showing the main components and connections of the circadian system of mammals.

pacemaker regulates the expression of rhythms (Rusak \& Zucker, 1979; Moore-Ede, Sulzman, \& Fuller, 1982; Morin, 1994; Miller, Morin, Schwartz, \& Moore, 1996; Moore, 1999; Cavalcante, Nascimento Jr., \& Costa, 2006; Golombek \& Rosenstein, 2010) (Figure 1).

\section{Suprachiasmatic nucleus}

The ventral hypothalamus contains a set of cells bilateral to the third ventricle, dorsal to the optic chiasm, called the suprachiasmatic nucleus (SCN) (Fig. 2). Because of its hypothalamic location and pattern of inputs and outputs, the SCN functions as a central CTS pacemaker, widely known as a "biological clock," in mammals. This term originated in studies from the 1970s when Moore and Lenn (1972) described the retinohypothalamic tract (RHT), which extends from the retina to the $\mathrm{SCN}$, and in subsequent studies demonstrating the importance of this pathway for synchronization. The evidence discovered by Moore and Lenn (1972) showed that synchronization to the light/dark cycle occurred through the retina and was mediated by the $\mathrm{SCN}$. Since then, the SCN has been the focus of continuing studies seeking to explain its function in synchronization mechanisms. These studies involved lesion techniques (Moore \& Eichler, 1972; Stephan \& Zucker, 1972), electrophysiology (Gillette, 1991), metabolism (Schwartz, 1991), and fetal tissue transplantation (Ralph, Foster, Davis, \& Menaker, 1991), in addition to neurochemical (Costa et al., 1998; Ramanathan, Nunez, Martinez, Schwartz \& Smale, 2006; Morin, 2007; Cavalcante et al., 2008; Nascimento Jr, Cavalcante, Cavalcante \& Costa 2010; Nascimento et al., 2010) and molecular studies (Ukai \& Ueda, 2010).

Studies that characterize neurochemical content show the existence of neuronal subpopulations within the SCN. A ventrolateral subpopulation receives direct projections from the retina through the RHT and from the thalamus through the geniculohypothalamic tract (GHT) and produces vasoactive intestinal polypeptide (VIP) as neurotransmitter.

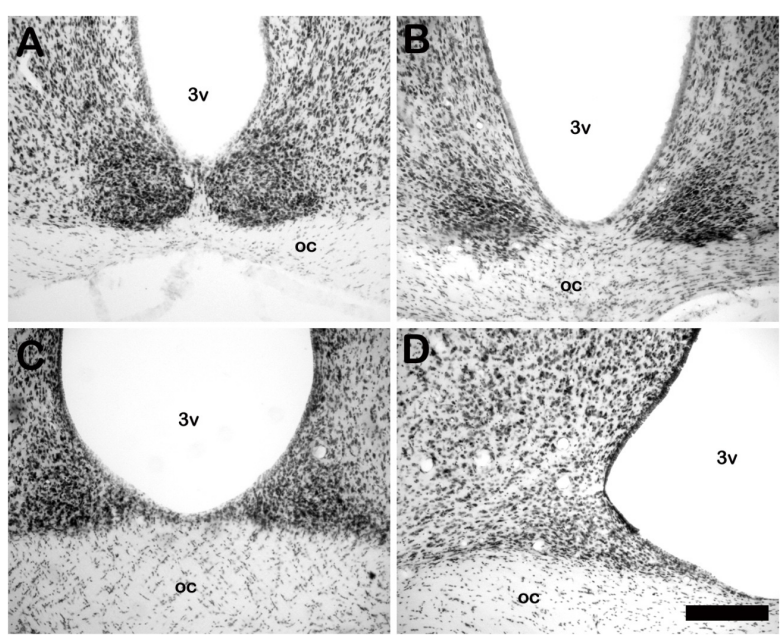

Figure 2. Digital images of coronal sections of Nissl staining of suprachiasmatic nuclei in the (A) mouse, (B) rat, (C) rock cavy, and (D) marmoset monkey. $3 \mathrm{v}$, third ventricle; oc, optic chiasm. Scale bar $=150 \mu \mathrm{m}$ in (A), (B), and (C). Scale bar $=80 \mu \mathrm{m}$ in (D). Digital images made in the Neuroanatomy Laboratory, Federal University of Rio Grande do Norte.

The dorsomedial subpopulation, which receives very few fibers from the RHT and GHT, produces vasopressin (VP) (Moore, 1993). This neurochemical characterization exhibits phylogenetic conservation, and these subpopulations are found in nearly all of the species studied (Cassone, Speh, Card, \& Moore, 1988; Wang et al., 1997; Costa et al., 1998; Goel, Lee, \& Smale, 1999; Smale \& Boverhof, 1999).

\section{Intergeniculate leaflet}

The SCN was considered the central pacemaker of circadian rhythmicity, but in the 1970s another component of the system was reported. Based on ${ }^{3} \mathrm{H}$-amino acid injection and autoradiographic development techniques, a number of laboratories described a thalamic projection to the $\mathrm{SCN}$ in rats and cats. This projection originates in the lateroventral geniculate nucleus (Swanson, Cowan, \& 
Jones, 1974; Riback \& Peters, 1975). Hickey and Spear (1976) used the retinal projection pattern to describe another structure in the lateral geniculate complex of the thalamus, the intergeniculate leaflet (IGL), a thin layer of cells located between the dorsal and ventral geniculate nucleus (Fig. 3). This study showed that the IGL receives bilateral retinal innervation. Neurochemical approaches have also been used to study the IGL. Other authors have reported that the IGL contains neuropeptide Y (NPY)producing neurons that project to the SCN (Card \& Moore, 1984; Harrington, Nance, \& Rusak 1985, 1987). The phase advances observed after NPY microinjections in the SCN during the subjective day suggested that this peptide was related to rhythmicity modulation (Moore, Gustafson, \& Card, 1984; Albers, Ferris, Leeman, \& Goldman, 1984).

\section{Synchronizing pathways}

For the SCN to be able to generate or synchronize circadian rhythms, environmental and physiological information uptake is necessary. This information is transmitted by synchronization pathways (afferent pathways). Three main synchronization pathways are characteristically found. One pathway, the RHT, originates in retinal ganglion cells, providing information on the light/ dark cycle (Moore \& Lenn, 1972; Moore, 1973; Johnson, Morin, \& Moore, 1988; Levine, Weiss, Rosenwasser, \& Miselis, 1991; Moga \& Moore, 1997; Goel et al., 1999; Costa et al., 1999; Cavalcante, Alves, Costa, \& Britto, 2002; Nascimento Jr., 2010). A second pathway, the GHT, which originates in the IGL, is the indirect conductor of photic information (Harrington et al., 1987; Moga \& Moore, 1997), performing its function through NPY (Harrington et al., 1985). The third pathway originates in the mesencephalic nuclei of the raphe, exerting its action through serotonin (5-hydroxytryptamine, 5-HT) (Ueda et al., 1983; Moga \& Moore, 1997; Cavalcante et al., 2002; Hay-Schmidt, Vrang, Larsen, \& Mikkelsen, 2003). This last synchronizing pathway of the $\mathrm{SCN}$ is the main focus of the present paper. It is inferred from observing serotonergic terminals in the SCN (Moore, Halaris, \& Jones, 1978; Ueda et al., 1983; van den Pol \& Tsujimoto, 1985; Moore \& Speh, 2004). Detailed studies of this projection were then conducted, starting with autoradiographic studies showing the dorsal and median raphe nuclei (Fig. 4) as being sources of this innervation (Azmitia \& Segal, 1978; Moore \& Speh, 2004). However, later studies show that the dorsal nucleus projects to the IGL (Moga \& Moore, 1997; Hay-Schmidt et al., 2003). Serotonin released by these nuclei intermediates the photic information that enters the SCN.

\section{Raphe and serotonin}

The set of neuronal clusters occupying the median line of the brainstem extends rostrocaudally between the interpeduncular nucleus in the mesencephalon and the decussation of pyramids in the medulla. The term "raphe" derives from the French raphé, meaning suture, and illustrates well the location of these nuclei. The studies in this area began when Ramon and Cajal
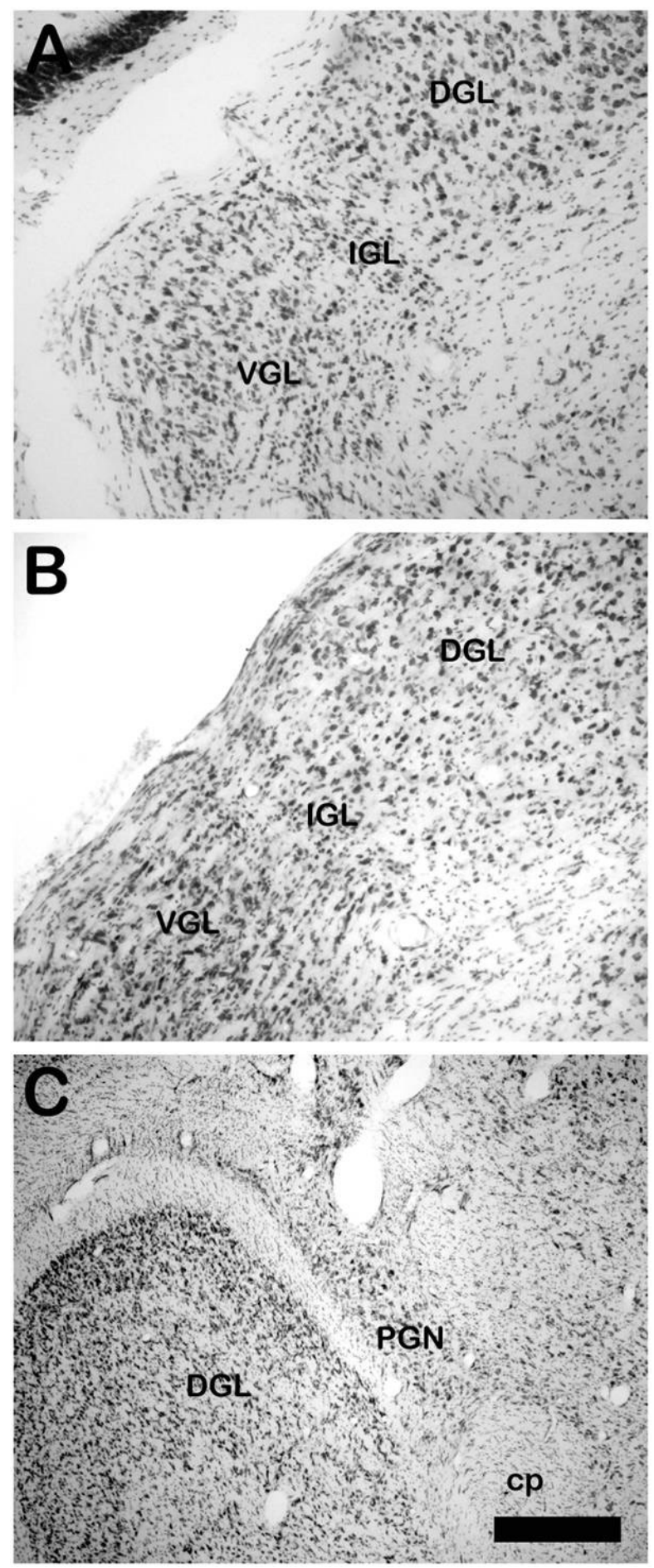

Figure 3. Digital images of coronal sections of Nissl staining of intergeniculate leaflet nuclei in (A) mouse and (B) rat (stippled line) and (C) pregeniculate nucleus in marmoset monkey (stippled line), the structural homolog to the IGL in rodents. cp, cerebral penducle; DGL, dorsal geniculate lateral nucleus; VGL, ventral geniculate lateral nucleus; IGL, intergeniculate leaflet; PGN, pregeniculate nucleus. Scale bar $=150 \mu \mathrm{m}$ in (A) and (B). Scale bar $=230 \mu \mathrm{m}$ in $(\mathrm{C})$. Digital images made in the Neuroanatomy Laboratory, Federal University of Rio Grande do Norte. 
described the cells of the brainstem, such as large multipolar neurons, with uncertain projections (for review, see Jacobs \& Azmitia, 1992). Interest increased when Dahlström and Fuxe (1964) described the presence of a monoaminergic neuronal system in the brainstem, showing a chain of catecholaminergic and serotonergic neurons. These authors suggested the designation of B1 to B9 in sequence caudal-rostral to the serotonergic nuclei. Further studies using immunohistochemical techniques allowed a better delineation of the raphe nuclei, detailing the serotonergic system (Brodal, Taber, \& Walberg 1960a, b; Taber, Brodal \& Walberg, 1960; Taber, 1961; Felten \& Cummings, 1979; Törk, 1985).

Representatives of all animal phyla that possess a nervous system exhibit serotonergic neurons. Along the phylogenetic scale, this molecule can act as a neurotransmitter, neuromodulator, or neurohormone regulating different behaviors. Characterization of 5-HT function appears to be more easily established in invertebrate species, whereas this amine is involved in more complex processes in vertebrates.

In coelenterates, one of the simplest systems that exhibit a nervous system, 5-HT appears to be involved in sensitivity, thus aiding locomotion in the animal (Anctil, 1989; Umbriaco, Anctil, \& Descarries, 1990). In platyhelminths, 5-HT-containing neurons are found in the central and peripheral nervous systems, controlling muscle contraction (Welsh, 1970; Halton, Maule, Johnston, \& Fairweather, 1987; Maule, Halton, Allen, \& Fairweather, 1989). One species of platyhelminths, Diclidophora merlangi, has gender-specific serotonergic innervation in the male reproductive system, suggesting the control of sexual behavior (Maule, Halton, Johnston, Shaw, \& Fairweather, 1990). A nematode widely used as a model for studying the nervous system, Caenorhabditis elegans, shows two serotonergic groups of neurons which are known as pharyngeal neurosecretory motor neurons that act by controlling feeding, locomotor activity, and sexual behavior (Horvitz, Chalfie, Trent, Sulston, \& Evans, 1982). The Aplysia californica, a mollusk species, has two large serotonergic groups of neurons in the cerebral ganglia that act on feeding behavior (Kupfermann \& Weiss, 1981). Serotonin in $A$. californica also plays a role on defensive behavior by modulating the muscle contraction of the withdrawal reflex (Glanzman et al., 1989; Hawkins \& Schacher, 1989). In annelids, serotonergic neurons project peripherally, acting as neurohormones controlling feeding behavior (Willard, 1981; Lent \& Dickinson, 1984). In lobsters, representatives of arthropods, 5-HT acts on the modulation of aggressive behavior that establish the relationships of dominance and subordination in social groups of animals (Beltz \& Kravitz, 1983). Serotonin also controls posture in lobsters and affects the circulatory system and digestive tract (Pasztor \& Bush, 1987; Battelle \& Kravitz, 1978). Serotonin is also found in echinoderms. In sea urchins, for example, it is mainly found in the larval stages, controlling the contraction and therefore mobility of larva (Bisgrove \& Burke, 1986; Gustafson, Lundgren, \& Treufeldt, 1972). In chordates, serotonergic neurons are organized in clusters that project for the entire central nervous system and peripheral organs, controlling a multitude of behaviors and neuroendocrine and cognitive functions (Tork \& Hornung, 1990). In this review, we focus on the role of 5-HT in biological rhythms in vertebrates.

A large proportion of neurons in the raphe system are 5-HT producers (Fig. 4). Nearly all 5-HT found in the central nervous system is produced in the raphe. Other neurotransmitters are produced in the raphe and may be co-localized with 5-HT. It also contains an extensive network of efferents, which explains why serotonergic terminals are found throughout the central nervous system, although this distribution varies for each area (Törk, 1985). The serotonergic system of the raphe is found in vertebrate species, although 5-HT is also found in invertebrates. The morphology of the raphe complex shows little variation in vertebrates (Törk, 1985). A wide variation in raphe nucleus terminology has been used over the years, but the system developed by Paxinos and Watson (1982) is currently used by most researchers.

\section{The raphe and circadian rhythmicity}

The raphe complex is considered a modulating component of circadian rhythmicity through serotonergic afferents sent to the SCN and IGL, whereas 5-HT is mainly responsible for CTS sensitivity to light.

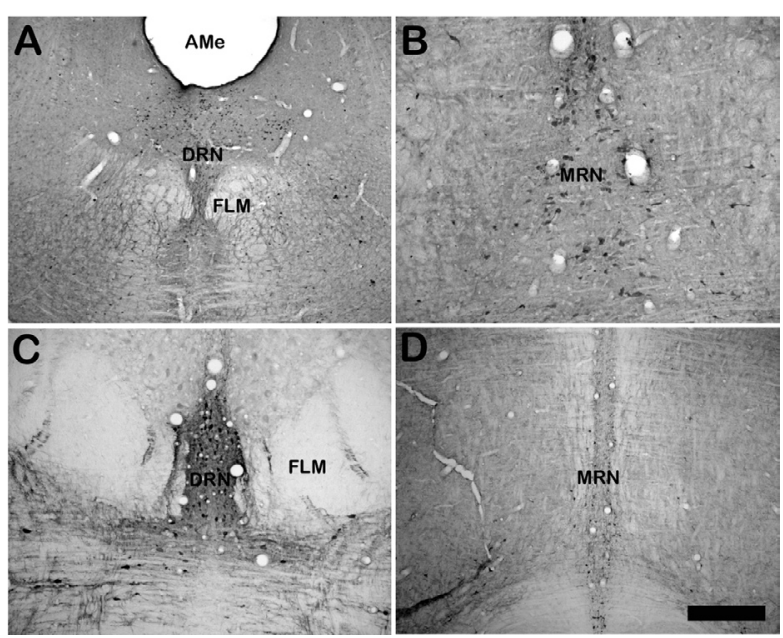

Figure 4. Digital images of coronal sections showing 5-HTimmunoreactive neurons in the dorsal raphe nucleus in (A) rat, (B) median raphe nucleus in rat, (C) dorsal raphe nucleus in marmoset monkey, and (D) median raphe nucleus in marmoset monkey. DRN, dorsal raphe nucleus; MRN, median raphe nucleus; FLM, medial longitudinal fascicule. Scale bar $=150$ $\mu \mathrm{m}$ in (A). Scale bar $=90 \mu \mathrm{m}$ in (B), (C), and (D). Digital images made in the Neuroanatomy Laboratory, Federal University of Rio Grande do Norte. 
This system must exhibit many characteristics to be considered a modulating component of rhythmicity, such as receiving retinal inputs, having connections with the SCN (and/or IGL), displaying circadian functions, and containing lesions that impair the maintenance of circadian rhythms. Ample evidence suggests that raphe nuclei are components of the CTS.

\section{Retinal afferents to the raphe}

Although rarely studied, the retinal projection to the DRN has been described since the 1970s in cats (Foote, Taber-Pierce, \& Edwards, 1978). Anterograde tracers injected into the rat retina showed retinal terminals in the most rostral portion of the DRN (Kawano, Decker, \& Reuss, 1996). Subsequent studies showed retinal terminals in the lateral portion of the DRN in rats (Fite et al., 1999). In gerbils (Meriones unguiculatus), extensive arborization of retinal terminals was observed in this nucleus (Fite, Janušonis, Foote, \& Bengston, 1999). Data also showed that retinal ganglion cells projecting to the DRN are partially the same cells that project to the lateral geniculate complex of the thalamus (Fite, Birkett, Smith, Janušonis, \& McLaughlin, 2003). In another rodent, Octodon degus, the retinal projection is concentrated in the dorsomedial and lateral portions of the DRN, with contralateral predominance (Fite \& Janušonis, 2001). In Cebus apella, a New World primate, a direct retinal projection to the DRN was also described (Frazão et al., 2008). Information from the retina may act on serotonergic DRN neuronal activity. Although this issue is still unclear, recent studies have sought to clarify the function of this innervation. For example, photostimulation with lowfrequency light led to reduced c-fos expression in the DRN of gerbils during the light phase of an artificial light/dark cycle (Fite, Wu, \& Bellemer, 2005). These results illustrate the importance of the retinal pathway for DRN neuronal activity.

\section{Connections with the SCN and IGL}

Several studies show efferent projections from the raphe to the SCN. However, nearly all of these studies are based on descriptions of serotonergic terminals found in the SCN (Fig. 5). In most of the species studied, the serotonergic inputs in the ventral portion of the SCN overlap with retinal terminals (Card \& Moore, 1984; van den Pol \& Tsujimoto, 1985; Cassone et al., 1988; Moore \& Speh, 2004). A New World primate (Callitrhix jacchus) shows a different serotonergic innervation pattern. This projection is concentrated in the dorsal portion of the SCN (Cavalcante et al., 2002; Pinato et al., 2007). The New World primate Cebus apella also does not exhibit well-defined organization of serotonergic terminals in the SCN (Pinato et al., 2007).
Reporting the presence of serotonergic terminals only partially solves the problem. The source of 5-HT found in the SCN must also be determined. After injection of Phaseolus vulgaris leucoagglutinin
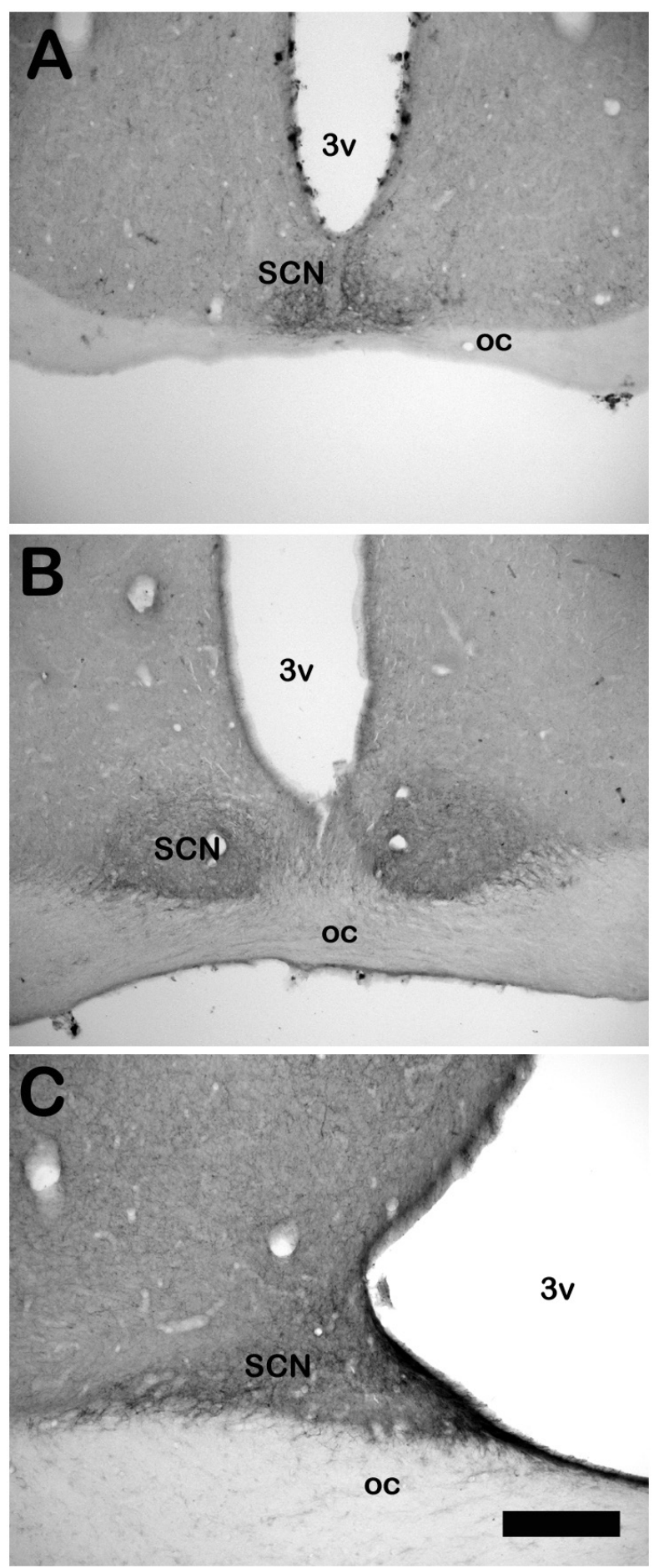

Figure 5. Digital images of coronal sections showing 5-HTimmunoreactive fibers/terminals in suprachiasmatic nuclei in (A) mouse, (B) rat, and (C) marmoset monkey. 3v, third ventricle; oc, optic chiasm; SCN, suprachiasmatic nuclei. Scale bar $=150 \mu \mathrm{m}$ in (A) and (B). Scale bar $=80 \mu \mathrm{m}$ in (D). Digital images made in the Neuroanatomy Laboratory, Federal University of Rio Grande do Norte. 
(PHAL), an anterograde tracer, into the median raphe nucleus (MRN), PHAL-immunoreactive (IR) fibers can be visualized in the ventral portion of the SCN (Meyer-Bernstein \& Morin, 1996; Hay-Schmidt et al., 2003). When the cholera toxin B subunit (CTb) is injected into the SCN, CTb-IR neurons are observed throughout the MRN, as well as in cells in the MRN and nucleus raphe obscurus (NRO) (Hay-Schmidt et al., 2003). Furthermore, electrostimulation of raphe nuclei causes an increase in 5-HT content in the SCN and IGL (Dudley, Dinardo, \& Glass, 1999).

Studies have also reported serotonergic projections to the IGL (Moore et al., 1978; Mantyh \& Kemp, 1983). These findings were confirmed in later experiments using a neuronal tracing technique. After injection of PHAL into the DRN, PHAL-IR terminals were found in the IGL and ventral lateral geniculate nucleus. When this tracer was injected into the IGL, CTb-IR neurons were observed in the DRN (Meyer-Bernstein \& Morin, 1996). The serotonergic projection that reaches the SCN clearly originates in the MNR, whereas the serotonergic terminals found in the IGL derive from the DRN (MeyerBernstein \& Morin, 1996).

\section{Circadian patterns in the raphe}

The raphe also displays its own circadian characteristics, such as tryptophan hydroxylase (TpH) concentration within the nucleus. This enzyme is a limiting factor in the formation of 5-HT. The peak expression of $\mathrm{TpH}$ is observed in the dark phase in animals maintained under an artificial light/dark cycle. The same profile is observed if animals are exposed to constant light conditions. Peak $\mathrm{TpH}$ activity in rats maintained in constant darkness occurs in the middle of the animal's subjective night (Malek, Pevet, \& Raison, 2004). Given the circadian variation of $\mathrm{TpH}$, we would also expect a circadian variation in serotonergic content. This variation has been studied since the 1960s. A daily variation of 5-HT was found in different areas of the encephalon (Quay, 1968). Variations in 5-HT content have been reported in the anterior raphe nuclei and regions innervated by these nuclei, such as the SCN (Cagampang, Yamazaki, Otori, \& Inouye, 1993; Cagampang \& Inouye, 1994; Portas et al., 1996). Rats maintained in an artificial light/dark cycle show a bimodal pattern with two peaks in 5-HT concentration in all raphe nuclei, especially the DRN. One of the peaks is observed in the animals' subjective night (Pinato, Ferreira, Markus, \& Nogueira, 2004). This study showed that the level of 5-HT starts to increase immediately after the onset of the dark phase in all raphe nuclei. Therefore, the production of 5-HT is also synchronized to the environment. Comparison of these data with Malek et al. (2004) shows a correlation between $\mathrm{TpH}$ and 5-HT peaks, although methodological differences between two experiments must be considered. Some data show circadian variation in different regions of the DRN in gerbils maintained under an artificial light/dark cycle, exhibiting higher peaks in the light/dark transition (Birkett \& Fite, 2005).

\section{Involvement of the raphe in circadian functions}

The circadian functions attributed to the raphe have been widely studied in recent years, partially because of the unclarified issues from earlier studies, such as those showing the DRN as the efferent source of 5-HT to the SCN. Recently published studies suggest that serotonergic input from the raphe is an inhibitor of the light response. However, we found that the raphe has a function in the sleep/wake cycle.

\section{The raphe and sleep}

The first studies that reported the importance of 5-HT in sleep control identified it as a "neurotransmitter of sleep." After electrophysiological studies were conducted to measure neuronal activity in the raphe, 5-HT was reported as a "neurotransmitter of wakefulness." In an experiment in which the brainstem of cats was sectioned at the pontine-mesencephalic level, a long period of insomnia (10 to 15 days) was observed in these animals (Jouvet, 1969). This was attributed to serotonergic terminal degeneration in the telencephalon. A correlation may also exist between MRN destruction and the reduced amount of slow-wave sleep and between paradoxical sleep (REM sleep) and the pontine raphe (PoRN) and magnum raphe (MaRN) nuclei (Jouvet, 1969). These experiments have been discredited because of the methodology used, given that a lesion of this magnitude causes serotonergic neuronal destruction, in addition to a large number of structures, such as blood vessels and fibers of passage. p-Chlorophenylalanine (PCPA) is capable of inhibiting TPH activity, which in turn impedes 5-HT synthesis. Thus, cats injected with PCPA showed total and prolonged insomnia (Koe \& Weissman, 1966).

Electrophysiological experiments in the 1970s showed that 5-HT does not modulate sleep itself. The recording of DRN neurons in cats demonstrated that this nucleus was completely active during wakefulness and that their activity started to decrease during slow-wave sleep until becoming nearly completely silent during paradoxical or REM sleep (McGinty \& Harper, 1976; Trulson \& Jacobs, 1979; Cespuglio, Faradji, Gomez, \& Jouvet, 1981). Dorsal raphe nucleus electrostimulation promotes wakefulness (Cespuglio et al., 1981). Cespuglio, Faradji, and Jouvet (1983) found that the volumetric signal of 5-hydroxyindolacetic acid increases in the cerebral cortex and thalamus during wakefulness and decreases during slow-wave sleep. Dorsal raphe nucleus activity in rats showed a gradual reduction in firing rate from wakefulness to REM sleep. This rate also diminished after systemic administration of 5-HT receptor agonists (Guzmán-Marín et al., 2000). 
Serotonin reuptake inhibitors are drugs used in antidepressive treatment. Polysomnographs of depressive patients show reduced REM sleep latency and decreased amounts of deep sleep (delta wave sleep). These inhibitors cause a reduction in paradoxical sleep, confirming the hypothesis of serotonergic inhibition during sleep (Ursin, 2002).

\section{The raphe and photic information}

Numerous studies have investigated the function of 5-HT in modulating the photic response of the SCN. These reports are based mainly on the manipulation of serotonergic transmission, in which 5-HT agonists or antagonists are used or specific serotonergic receptors are deactivated and the CTS response to photic information is measured. This modulation can be assumed if we consider that in most species, serotonergic terminals are co-localized with retinal terminals in the SCN. Some authors showed that light-induced phase shifts can be attenuated or even blocked by the injection of 5-HT agonists (Selim, Glass, Hauser, \& Rea, 1993; Glass, Selim, \& Rea, 1994; Rea, Glass \& Colwell, 1994; Rea, Barrera, Glass \& Gannon, 1995). Light-induced behavioral changes are not the only ones attenuated by 5-HT. Meyer-Bernstein \& Morin (1999) demonstrated that the c-fos expression in the SCN is inhibited after electrical stimulation of the DRN and MNR.

In an experiment that destroyed serotonergic neurons in the MNR, Meyer-Bernstein, Blanchard and Morin (1997) showed an increased activity period in animals submitted to light-dark cycle when they received an injection of 5-7-dihydroxytryptamine (DHT), exhibiting phase advances at the onset of activity and delays at the end. When this lesion targeted serotonergic terminals in the SCN, the animals showed phase advances at activity onset. This study also shows that even a few serotonergic fibers in the SCN allow slight synchronization of the light/ dark cycle. The authors reported that the activity period in the light/dark cycle is maintained by the MNR. Similar results were found by other researchers that treated hamsters and mice with DHT. Hamsters showed phase delays as a response to light pulses between circadian times (CT) 13 and 15. Mice exhibited phase delays upon receiving light pulses between CT 12 and 30 (Bradbury, Dement, \& Edgar, 1997; Morin \& Blanchard, 2001).

Serotonin agonists also cause a reduction in SCN neuronal firing rate, reducing their capacity to synchronize to the light/dark cycle. These effects appear to be mediated by specific receptors. The application of 8-OH-DPAT reduces the firing rate of action potentials in the SCN after optic nerve stimulation, inhibits the expression of Fos in the SCN, and dose-dependently attenuates phase shifts caused by an activity wheel (Rea et al., 1994). The inhibitory effects of 8-OH-DPAT occur in the SCN and are not only expressed through the $5-\mathrm{HT}_{2}$ receptor, but also act through the $5-\mathrm{HT}_{1 \mathrm{~A}}$ and
5-HT 7 receptors (Weber, Gannon, \& Rea, 1998). When quipazine, a 5-HT agonist, is applied in vitro to the $\mathrm{SCN}$, it induces alterations in the firing rate of its neurons as well as 8-OH-DPAT application (Prosser, Miller, \& Heller, 1990; Medanic \& Gillette, 1992). Curiously, these effects are observed during the subjective day. The in vivo application of these same agonists caused phase advances in free-running locomotor activity in rats and hamsters (Tominaga, Shibata, Ueki, \& Watanabe, 1992; Edgar, Miller, Prosser, Dean, \& Dement, 1993; Cutrera, Ouarour, \& Pevet, 1994).

Drug experiments have also demonstrated the function of 5-HT in the light response. Treatment with clorgyline, an antidepressant and 5-HT uptake inhibitor, attenuates light-induced phase shifts (Duncan, Johnson, \& Wehr, 1998). Clomipramine, a drug causing depressive symptoms, provokes changes in circadian rhythms, resulting in less synchronization to the light/ dark cycle and a reduced light response at the end of the subjective night (Yannielli, Cutrera, Cardinali, \& Golombek, 1998).

Of the 5-HT receptors found in the $\mathrm{SCN}, 5-\mathrm{HT}_{1 \mathrm{~B}}$ stands out for its location on retinal terminals, a topography that promotes the modulation of light entering the SCN. Bilateral enucleation reduces the number of $5-\mathrm{HT}_{1 \mathrm{~B}}$ binding sites by 35\% (Pickard, Weber, Scott, Riberdy, \& Rea, 1996; Pickard et al., 1999). Activation of these receptors attenuates light-induced phase shifts (Pickard et al., 1996). The application of agonists from this receptor inhibits phase shifts and light-induced c-fos expression in the SCN (Glass et al., 1994; Pickard et al., 1996). 5-HT $1 \mathrm{~B}$ knockout mice have attenuated lightinduced c-fos expression in the SCN at CT 16 and 23 (Sollars, Simpson, Ogilvie, \& Pickard, 2006).

\section{The raphe may be related to food synchronization}

Serotonin is a derivative of tryptophan and as such is affected by food restriction cycles, given that food is a source of tryptophan for the organism. Food deprivation leads to a reduction in serotonergic content in both the raphe and hypothalamic areas (Kang, Park, Ahn, \& Huh, 2001). This serotonergic depression in the hypothalamus may be one of the causes of the behavioral alterations observed in animals subjected to a food restriction regimen. The synthesis of melatonin, a hormone derived from 5-HT, undergoes phase advances in rats subjected to food restriction (Challet, Pevet, Vivien-Roels, \& Malan, 1997). In an experiment with rats subjected to food restriction and divided into three groups (one group that had no access to food but had olfactory and visual contact; one group that had food access for $30 \mathrm{~min}$; and one group with food access for $2 \mathrm{~h}$ ), an increase in c-fos expression was observed in the caudal raphe nuclei of the pallid raphe nucleus, nucleus raphe magnus, and nucleus raphe obscurus during the period of food exposure (Takase, Barone, \& Nogueira, 2000). 
Leptin is a product of adipocyte secretion, which is related to the control of body weight, metabolism, and reproduction (Friedman \& Halaas, 1998). Leptin injection led to a reduction in food ingestion (TangChristensen, Havel, Jacobs, Larsen \& Cameron, 1999). Finn, Cunningham, Rickard, Clifton and Steiner (2001) found leptin receptors in caudal linear nuclei (CLN), DRN, and MRN, which may confirm the importance of the raphe in food synchronization. With respect to this possible function, studies are scarce and their findings have been inconclusive. Nevertheless, this possibility cannot be excluded.

We already discussed that light is the most potent cue for the entrainment of the SCN. Temporally restricted feeding (i.e., limited duration of daily food access) is a strong synchronizer for rhythmic gene expression in peripheral oscillators (Damiola et al., 2000; Stokkan, Yamazaki, Tei, Sakaki, \& Menaker, 2001). Under constant darkness conditions (but not in a light/dark cycle), temporally restricted feeding or a palatable diet in addition to regular food ad libitum is able to entrain the SCN clock (Mistlberger, 1994; Mistlberger \& Holmes, 2000; Mendoza, Angeles-Castellanos, \& Escobar, 2005).

The ability to entrain circadian rhythms to food availability is important for survival. Food-entrained circadian rhythms are characterized by increased locomotor activity in anticipation of food availability (food anticipatory activity). However, the molecular components and neural circuitry underlying the regulation of food anticipatory activity remain unclear.

Serotonin has been implicated in the control of eating behavior and body weight. Stimulants of this monoamine reduce food intake and weight gain and increase energy expenditure, both in animals and humans. This phenomenon is partially mediated by 5-HT receptors located in various medial hypothalamic nuclei, most notably the paraventricular nucleus (PVN), ventromedial nucleus (VMN), and $\mathrm{SCN}$, and to a more variable extent, the dorsomedial nucleus (DMN). These nuclei are essential for the normal control of nutrient intake, and the presence of exogenous 5-HT as well as agents that enhance synaptic availability of endogenous $5 \mathrm{HT}$ in these areas has a suppressive effect on food intake (Weiss et al., 1991) and enhance energy metabolism (Sakaguchi \& Bray, 1989). It also increases circulating levels of glucose and corticosterone (Scheurink, Leuvenink, \& Steffens, 1993).

Serotonin plays a specific role in controlling the temporal aspects of feeding, producing a significant decrease in the size and duration of individual meals in association with a reduced rate of eating, but with no effect on meal latency or frequency (Leibowitz, Weiss, \& Shor-Posner, 1988). The hypothalamic 5-HT system is within a negative feedback loop that controls eating behavior. The ingestion of carbohydrates stimulates the production of the monoamine, which then performs the function of terminating the ingestion of this nutrient and producing satiety.

Can these actions of 5-HT help us understand its relationship to the modulation of non-photic stimuli, or can eating behavior, similar to a strong non-photic synchronizer, modulate 5-HT rhythm? Experiments indicate that a rhythm of serotonergic activity, with regard to feeding behavior, exists across the light/dark cycle, reflected by temporal shifts in responsiveness to medial hypothalamic 5-HT receptor stimulation and the release and utilization of endogenous 5-HT. The strongest serotonergic activity occurs at the beginning of the active feeding period at the transition between light and dark (Leibowitz et al., 1988; Weiss et al., 1991). Extracellular levels of 5-HT in the SCN are highest early in the night when locomotor behavior is activated by the dark phase in rats and hamsters (Shioiri, Takahashi, Yamada, \& Takahashi, 1991; Cagampang \& Inouye, 1994; Dudley, Di Nardo, \& Glass, 1998). Moreover, 5-HT release at the level of the SCN is suppressed by novel wheel running activity late in the subjective night.

At the onset of the dark phase, the active phase for the freely feeding rat, serotonergic stimulation of the PVN or SCN is most effective in suppressing food intake and particularly carbohydrate ingestion (Weiss, Rogacki, Fueg, Buchen, \& Leibowitz, 1990). Moreover, carbohydrate ingestion is most effective at the onset of the feeding period in enhancing 5-HT synthesis in the brain (Fernstrom \& Fernstrom, 1995). Hypothalamic serotonergic control of feeding is expressed phasically primarily at the beginning of the natural feeding cycle when endogenous 5-HT activity peaks (Faradji, Cespuglio, \& Jouvet, 1983; Hery, Faudon, Dusticier, \& Hery, 1982; Martin, 1991; Pinato et al., 2004).

Therefore, 5-HT may be proposed to play a specific role in terminating meals by stimulating PVN satiety neurons (Sclafani \& Aravich, 1983) and SCN neurons that determine this circadian rhythm (Faradji et al., 1983).

Some of the action of 5-HT may occur outside the SCN. The role of extra-SCN areas in setting the circadian phase is under investigation (Vansteensel et al., 2003), and one study suggests that the effects of novel wheel exposure involve extra-SCN processing (Yannielli \& Harrington, 2000).

\section{Effects of raphe lesions on circadian rhythms}

The connections between the raphe and central components of the CTS are well established, but what would be the effect of raphe nucleus lesions on SCN or IGL activity and behavioral responses? The first studies that attempted to answer these questions showed that circadian rhythm amplitude decreases and synchronization to the light/dark cycle becomes less evident after raphe nuclei lesions. These results depend on the specific site where the lesion was applied. However, these animals still showed traces of synchronization and some circadian rhythms (Block 
\& Zucker, 1976; Kam \& Moberg, 1977). Levine, Rosenwasser, Yanovski, and Adler (1986) conducted an experiment that assessed the effect of MRN lesions on the CTS during prolonged behavioral observation of synchronized or free-running rats. The results showed the importance of the DRN and MRN in the expression of free-running circadian rhythms. After being subjected to raphe lesions, rats kept in constant darkness showed shorter periods than when they were maintained in constant light. Free-running rhythm is expressed in the first few days after surgery, becoming increasingly less evident until there is no discernible rhythmic pattern of locomotor activity (Levine et al., 1986). In this study, the lesion was very large, encompassing other brainstem structures. Additionally, the destruction of serotonergic terminals in the SCN of animals kept under a light/dark cycle neither altered synchronization to this cycle nor impeded phase advances provoked by activity wheels (Bobrzynska, Vrang, \& Mrosovsky, 1996).

Other neuropharmacological studies used methylenedioxymethamphetamine (MDMA, ecstasy) as a neurotoxin for serotonergic terminals. The results of these investigations showed a reduction in the phase advances of SCN neuronal firing as a response to the application of 8-OH-DPAT (Biello \& Dafters, 2001; Colbron, Jones, \& Biello, 2002).

The IGL also undergoes alterations after DRN lesion. After provoking electrolytic lesions in the DRN of rats, Blasiak and Lewandowski (2003) observed an increase in IGL neuronal firing rate. These investigators also found that electrostimulation of the DRN causes a transient and reversible decrease in IGL neuronal firing rate.

\section{Final considerations}

The raphe maintains a narrow anatomical and functional relationship with the central components of the CTS, taking part in important circadian functions, such as sleep/wake regulation or light/dark cycle synchronization, attributable to modulation of light information. The raphe is a complex that receives a range of sensory information, demonstrated in the organization of the afferents it receives, making it an important integrating center between the CTS and environment. Specific nuclear lesions lead to altered circadian rhythms. Pharmacological experiments show that the functions performed by the raphe in synchronization occur through 5-HT.

The literature shows that the main raphe nuclei involved in circadian functions are the DRN and MRN, based on the connections of these nuclei with the IGL and SCN, respectively. Lesions of these nuclei cause significant alterations in SCN and IGL activity. Stimulation of these raphe nuclei was also effective at revealing their participation in rhythmicity.

The literature also shows that the actions of 5-HT depend on the type of postsynaptic receptor. Interest has focused mainly on the $5-\mathrm{HT}_{1 \mathrm{~B}}$ receptor because of the apparent importance of this receptor in the light response. Many questions remain unanswered, such as the function of the raphe in food synchronization, the mechanisms by which the raphe acts in controlling the sleep/wake cycle, and whether receptors are involved in modulating non-photic responses. Researchers are actively seeking answers to these questions. According to the literature, we can confirm that the raphe has important functions in the CTS and that the absence of specific raphe or 5-HT nuclei hinders the maintenance of rhythms coordinated by the CTS.

\section{Acknowledgements}

This study was supported by CNPq, CAPES, PROPESQ-UFRN, and FAPESP.

\section{References}

Albers, H.E., Ferris, C.F., Leeman, S.E., \& Goldman, B.D. (1984). Avian pancreatic polypeptide phase shifts hamster circadian rhythms when microinjected into the suprachiasmatic region. Science, 223, 833-835.

Anctil, M. (1989). Modulation of a rhythmic activity by serotonin via cyclic AMP in the coelenterate Renilla köllikeri. Journal of Comparative Physiology B, 159, 491-500.

Azmitia, E.C., \& Segal, M. (1978). An autoradiographic analysis of the differential ascending projections of the dorsal and median raphe nuclei in the rat. Journal of Comparative Neurology, 179, 641-667.

Battelle, B.A., \& Kravitz, E.A. (1978). Targets of octopamine action in the lobster: cyclic nucleotide changes and physiological effects in hemolymph, heart and exoskeletal muscle. Journal of Pharmacology and Experimental Therapeutics, 205, 438-448.

Beltz, B.S., \& Kravitz, E.A. (1983). Mapping of serotonin-like immunoreactivity in the lobster nervous system. Journal of Neuroscience, 3, 585-602.

Biello, S.M., \& Dafters, R.I. (2001). MDMA and fenfluramine alter the response of the circadian clock to a serotonin agonist in vitro. Brain Research, 920, 202-209.

Birkett, M., \& Fite, K.V. (2005). Diurnal variation in serotonin immunoreactivity in the dorsal raphe nucleus. Brain Research, 1034, 180-184.

Bisgrove, B.W., \& Burke, R.D. (1986). Development of serotonergic neurons in embryos of the sea urchin, Strongylocentrotus purpuratus. Development, Growth and Differentiation, 28, 569-574.

Blasiak, T., \& Lewandowski, M.H. (2003). Dorsal raphe nucleus modulates neuronal activity in rat intergeniculate leaflet. Behavioural Brain Research, 138, 179-185.

Block, M., \& Zucker, I. (1976). Circadian rhythms of rat locomotor activity after lesions of the midbrain raphe nuclei. Journal of Comparative Physiology, 109, 235-247

Bobrzynska, K., Vrang, N., \& Mrosovsky, N. (1996). Persistence of nonphotic phase shifts in hamsters after serotonin depletion in the suprachiasmatic nucleus. Brain Research, 741, 205-214.

Bradbury, M.J., Dement, W.C., \& Edgar, D.M. (1997). Serotonincontaining fibers in the suprachiasmatic hypothalamus attenuate light-induced phase delays in mice. Brain Research, 768, 125-134.

Brodal, A., Taber, E., \& Walberg, F. (1960a). The raphe nuclei of the brain stem in the cat: II. Efferent connections. Journal of Comparative Neurology, 114, 239-259.

Brodal, A., Taber, E., \& Walberg, F. (1960b). The raphe nuclei of the brain stem in the cat: III. Afferent connections. Journal of Comparative Neurology, 114, 261-281.

Cagampang, F.R.A., Yamazaki, S., Otori, Y., \& Inouye, S.I.T. (1993). Serotonin in the raphe nuclei: regulation by light and an endogenous pacemaker. Neuroreport, 4, 49-52.

Cagampang, F.R.A., \& Inouye, S.I.T. (1994). Diurnal and circadian changes of serotonin in the suprachiasmatic nuclei: regulation by light and an endogenous pacemaker. Brain Research, 639, 175-179. 
Card, J.P., \& Moore, R.Y. (1984). The suprachiasmatic nucleus of the golden hamster: immunohistochemical analysis of cell and fiber distribution. Neuroscience, 13, 415-431.

Cassone, V.M., Speh, J.C., Card, J.P., \& Moore, R.Y. (1988). Comparative anatomy of the mammalian hypothalamic suprachiasmatic nucleus. Journal of Biological Rhythms, 3, 71-91.

Cavalcante, J.S., Alves, A.S., Costa, M.S.M.O., \& Britto, L.R.G. (2002). Differential distribution of afferent containing serotonin and neuropeptide $\mathrm{Y}$ within the marmoset suprachiasmatic nucleus. Brain Research, 927, 200-203.

Cavalcante, J.S., Nascimento Júnior, E.S., \& Costa, M.S.M.O. (2006). Componentes centrais do sistema de temporização circadiana: o núcleo supraquiasmático e o folheto intergeniculado. Neurociências, 3, 1-10.

Cavalcante, J.S., Britto, L.R.G., Toledo, C.A.B., Nascimento, E.S., Jr., Lima, R.R.M., Pontes, A.L.B., \& Costa, M.S.M.O. (2008). Calciumbinding proteins in the circadian centers of the common marmoset (Callithrix jacchus) and the rock cavy (Kerodon rupestris) brains. Brain Research Bulletin, 76, 354-360.

Cespuglio, R., Faradji, H., Gomez, M.E., \& Jouvet, M. (1981). Single unit recordings in the nuclei raphe dorsalis and magnus during the sleep-waking cycle of semi-chronic prepared cats. Neuroscience Letters, 24, 133-138

Cespuglio, R., Faradji, H., \& Jouvet, M. (1983). Voltammetric detection of 5-hydroxyindole cmpound present at the extracellular levels of the cell-bodies and the terminals of the serotoninergic system-fluctuations during the sleep-waking cycle in chronically implanted rats. Comptes Rendus De L Academie Des Sciences Serie III-Sciences De La Vie-Life Sciences, 296, 611-616.

Challet, E., Pévet, P., Vivien-Roels, B., \& Malan, A. (1997). Phaseadvanced daily rhythms of melatonin, body temperature, and locomotor activity in food-restricted rats fed during daytime. Journal of Biological Rhythms, 12, 65-79.

Colbron, S., Jones, M., \& Biello, S.M. (2002). MDMA alters the response of the circadian clock to a photic and non-photic stimulus. Brain Research, 956, 45-52.

Costa, M.S.M.O., Moreira, L.F., Alones, V., Lu, J., Santee, U.R., Cavalcante, J.S., Moraes, P.R.A., ... Menaker, M. (1998). Characterization of the circadian system in a brazilian species of monkey (Callithrix jacchus): immunohistochemical analysis and retinal projections. Biological Rhythm Research, 29, 510-520.

Costa, M.S.M.O., Santee, U.R, Cavalcante, J.S., Moraes, P.R.A., Santos, N.P., \& Britto, L.R.G. (1999). Retinohypothalamic projections in the commom marmoset (Callitrhix jacchus): a study using cholera toxin subunit B. Journal of Comparative Neurology, 415, 393-403.

Cutrera, R.A., Ouarour, A., \& Pévet, P. (1994). Effects of the 5HT receptor agonist 8-OH-DPAT and other non-photic stimuli on the circadian rhythm of wheel-running activity in hamsters under different constant conditions. Neuroscience Letters, 172, 27-30.

Dahlström, A., \& Fuxe, K. (1964). Evidence for the existence of monoamine-containing neurons in the central nervous system: I Demonstration of monoamines in the cell bodies of brain stem neurons. Acta Physiologica Scandinavica Supplementum, 232, 1-55.

Damiola, F., Le Minh, N., Preitner, N., Kornmann, N., Fleury-Olela, F., \& Schibler, U. (2000). Restricted feeding uncouples circadian oscillators in peripheral tissues from the central pacemaker in the suprachiasmatic nucleus. Genes and Development, 14, 2950-2961.

Dudley, T.E., Di Nardo, L.A., \& Glass, J.D. (1998). Endogenous regulation of serotonin release in the hamster suprachiasmatic nucleus. Journal of Neuroscience, 18, 5045-5052.

Dudley, T.E., Dinardo, L.A., \& Glass, J.D. (1999). In vivo assessment of the midbrain raphe nuclear regulation of serotonin release in the hamster suprachiasmatic nucleus. Journal of Neurophysiology, 81, 1469-1477.

Duncan, W.C., Jr., Johnson, K.A., \& Wehr, T.A. (1998). Decreased sensitivity to light of the photic entrainment pathway during chronic clorgyline and lithium treatments. Journal of Biological Rhythms, 13, 330-346.

Edgar, D.M., Miller, J.D., Prosser, R.A., Dean, R.R., \& Dement, W.C. (1993). Serotonin and the mammalian circadian system: II. Phase shifting rat behavioral rhythms with serotonergic agonists. Journal of Biological Rhythms, 8, 17-31.

Faradji, H., Cespuglio, R., \& Jouvet, M. (1983). Voltammetric measurements of 5-hydroxyindole compounds in the suprachiasmatic nuclei: circadian fluctuations. Brain Research,
279, 111-119.

Felten, D.L., \& Cummings, J.P. (1979). The raphe nuclei of the rabbit brain stem. Journal of Comparative Neurology, 187, 199-243.

Finn, P.D., Cunningham, M.J., Rickard, D.G, Clifton, D.K., \& Steiner, R.A. (2001). Serotonergic neurons are targets for leptin in the monkey. Journal of Clinical Endocrinology and Metabolism, 86, 422-426.

Fite, K.V., Janušonis, S., Foote, W., \& Bengston, L. (1999). Retinal afferents to the dorsal raphe nucleus in rats and Mongolian gerbils. Jounal of Comparative Neurology, 414, 469-484.

Fite, K.V., \& Janušonis, S. (2001). Retinal projections to the dorsal raphe nucleus in the Chilean degus (Octodon degus). Brain Research, 895, 139-145.

Fite, K.V., Birkett, M.A., Smith, A., Janušonis. S., \& McLaughlin, S. (2003). Retinal ganglion cells projecting to the dorsal raphe and lateral geniculate complex in Mongolian gerbils. Brain Research, 973, 146-150.

Fite, K.V., Wu, P.S., \& Bellemer, A. (2005). Photostimulation alters c-Fos expression in the dorsal raphe nucleus. Brain Reserch, 1031, 245-252.

Foote, W.E., Taber-Pierce, E., \& Edwards, L. (1978). Evidence for retinal projection to the midbrain raphe of the cat. Brain Research, $156,135-140$

Fernstrom, M.H., \& Fernstrom, J.D. (1995). Brain tryptophan concentrations and serotonin synthesis remain responsive to food consumption after the ingestion of sequential meals. American Journal of Clinical Nutrition, 61, 312-319.

Frazão, R., Pinato, L., Silva, A.V., Britto, L.R.G., Oliveira, J.A., \& Nogueira, M.I. (2008). Evidence of reciprocal connections between the drosal raphe nucleus and the retina in the monkey (Cebus apella). Neuroscience Letters, 430, 119-123.

Friedman, J.M., \& Halaas, J.L. (1998). Leptin and the regulation of body weight in mammals. Nature, 395, 763-770.

Gillette, M.U. (1991). SCN electrophysiology in vitro: rhythmic activity and endogenous clock properties. In D.C. Klein, R.Y. Moore, \& S.M. Reppert (Eds.), Suprachiasmatic nucleus: the mind's clock (pp. 43-125). Oxford: Oxford University Press.

Glanzman, D.L., Mackey, S.L., Hawkins, R.D., Dyke, A.M., Lloyd, P.E., \& Kandel, E.R. (1989). Depletion of serotonin in the nervous system of Aplysia reduces the behavioral enhancement of gill withdrawal as well as the heterosynaptic facilitation produced by tail shock. Journal of Neuroscience, 9, 4200-4213.

Glass, J.D., Selim, M., \& Rea, M.A. (1994). Modulation of lightinduced c-fos expression in the suprachiasmatic nuclei by 5 -HT receptor agonists. Brain Research, 638, 235-242.

Goel, N., Lee, T.M., \& Smale, L. (1999). Suprachiasmatic nucleus and intergeniculate leaflet in the diurnal rodent Octodon degus: retinal projections and immunocytochemical characterization. Neuroscience, 92, 1491-1509.

Golombek, D.A., \& Rosenstein, R.E. (2010). Physiology of circadian entrainment. Physiological Reviews, 90, 1063-1102.

Gustafson, T., Lundgren, B., \& Treufeldt, R. (1972). Serotonin and contractile activity in the echinopluteus: a study of the cellular basis of larval behaviour. Experimental Cell Research, 72, 115-139.

Guzmán-Marín, R., Alam, M.N., Szymusiak, R., Drucker-Colín, R., Gong, H., \& McGinty, D. (2000). Discharge modulation of rat dorsal raphe neurons during sleep and waking: effects of preoptic/ basal forebrain warming. Brain Research, 875, 23-34.

Halton, D.W., Maule, A.G., Johnston, C.F., \& Fairweather, I. (1987). Occurrence of 5-hydroxytryptamine (serotonin) in the nervous system of a monogenean, Diclidophora merlangi. Parasitology Research, 74, 151-154.

Harrington, M.E., Nance D.M., \& Rusak, B. (1985). Neuropeptide Y immunoreactivity in the hamster geniculo-suprachiasmatic tract. Brain Research Bulletin, 15, 465-472.

Harrington, M.E., Nance, D.M., \& Rusak, B. (1987). Double-labeling of neuropeptide Y-immunoreactive neurons which project from the geniculate to the suprachiasmatic nucleus. Brain Research, 410, 275-282.

Hawkins, R.D., \& Schacher, S. (1989). Identified facilitator neurons L29 and L28 are excited by cutaneous stimuli used in dishabituation, sensitization, and classical conditioning of Aplysia. Journal of Neuroscience, 9, 4236-4245.

Hay-Schmidt, A., Vrang, N., Larsen, P.J., \& Mikkelsen, J.D. (2003). Projections from the raphe nuclei to the suprachiasmatic nuclei of the rat. Journal of Chemical Neuroanatomy, 25, 293-310.

Hery, M., Faudon, M., Dusticier, G., \& Hery, F. (1982). Daily variations in 
serotonin metabolism in the suprachiasmatic nucleus of the rat: influence of oestradiol impregnation. Journal of Endocrinology, 94, 157-166.

Hickey, T.L., \& Spear, P.D. (1976). Retinogeniculate projections in hooded and albino rats: an autoradiographic study. Experimental Brain Research, 24, 523-529.

Horvitz, H.R., Chalfie, M., Trent, C., Sulston, J.E., \& Evans, P.D. (1982). Serotonin and octopamine in the nematode Caenorhabditis elegans. Science, 216, 1012-1014.

Jacobs, B.L., \& Azmitia, E.C. (1992). Structure and function of the brain serotonin system. Physiological Reviews, 72, 165-229.

Johnson, R.F., Morin, L.P., \& Moore, R.Y. (1988). Retinohypothalamic projections in the hamster and rat demonstrated using cholera toxin. Brain Research, 462, 301-312.

Jouvet, M. (1969). Biogenic amines and the states of sleep. Science, 163, 32-41.

Kam, L.M., \& Moberg, G.P. (1977). Effect of raphe lesions on the circadian pattern of wheel running in the rat. Physiology and Behavior, 18, 213-217.

Kang, M., Park, C., Ahn, H., \& Huh, Y. (2001). Ectopic expression of serotonin-positive neurons in the hypothalamus associated with a significant serotonin decrease in the midbrain of food restricted rats. Neuroscience Letters, 314, 25-28.

Kawano, H., Decker, K., \& Reuss, S. (1996). Is there a direct retinaraphe-suprachiasmatic nucleus pathway in the rat? Neuroscience Letters, 212, 143-146.

Koe, B.K., \& Weissman, A. (1966). p-Chlorophenylalanine, a specific depletor of brain serotonin. Journal of Pharmacology and Experimental Therapeutics, 154, 499-516.

Kupfermann, I., \& Weiss, K.R. (1981). The role of serotonin in arousal of feeding behavior of Aplysia. In B.L. Jacobs, \& A. Gelperin (Eds.), Serotonin neurotransmission and behavior (pp. 255-287). Cambridge: MIT Press.

Leibowitz, S.F., Weiss, G.F., \& Shor-Posner, G. (1988). Hypothalamic serotonin: pharmacological, biochemical, and behavioral analyses of its feeding-suppressive action. Clinical Neuropharmacology, 11( Suppl 1), S51-S71.

Lent, C.M., \& Dickinson, M.H. (1984). Serotonin integrates the feeding behavior of the medicinal leech. Journal of Comparative Physiology A, 154, 457-471.

Levine, J.D., Weiss, M.L., Rosenwasser, A.M., \& Miselis, R.R. (1991). Retinohypothalamic tract in the female albino rat: a study using horseradish peroxidase conjugated to cholera toxin. Journal Comparative Neurology, 306, 344-360.

Levine, J.D., Rosenwasser, A.M., Yanovski, J.A., \& Adler, N.T. (1986). Circadian activity rhythms in rats with midbrain raphe lesions. Brain Research, 384, 240-249.

Malek, Z.S., Pévet, P., \& Raison, S. (2004). Circadian change in tryptophan hydroxylase levels within the rat intergeniculate leaflets and raphe nuclei. Neuroscience, 125, 749-758.

Martin, K.F. (1991). Rhythms in neurotransmitter turnover: focus on the serotonergic system. Pharmacology and Therapeutics, 51, 421-429.

Mantyh, P.W., \& Kemp, J.A. (1983). The distribution of putative neurotransmitters in the lateral geniculate nucleus of the rat. Brain Research, 288, 344-348.

Marques, N., Golombek, D., \& Moreno, C. (2003). Adaptação temporal. In: N. Marques, \& L. Menna-Barreto (Eds.), Cronobiologia: princípios e aplicações (pp. 55-98). São Paulo: Editora da Universidade de São Paulo.

Maule, A.G., Halton, D.W., Allen, J.M., \& Fairweather, I. (1989). Studies on motility in vitro of an ectoparasitic monogenean, Diclidophora merlangi. Parasitology, 98, 85-93.

Maule, A.G., Halton, D.W., Johnston, C.F., Shaw, C. \& Fairweather, I. (1990). A cytochemical study of the serotoninergic, cholinergic and peptidergic components of the reproductive system in the monogenean parasite, Diclidophora merlangi. Parasitology Research, 76, 409-419.

McGinty, D.J., \& Harper, R.M. (1976). Dorsal raphe neurons: depression of firing during sleep in cats. Brain Research, 101, 569-575.

Medanic, M., \& Gillette, M.U. (1992). Serotonin regulates the phase of the rat suprachiasmatic circadian pacemaker in vitro only during the subjective day. Journal of Physiology, 450, 629-642.

Mendoza, J., Angeles-Castellanos, M., \& Escobar, C. (2005) A daily palatable meal without food deprivation entrains the suprachiasmatic nucleus of rats. European Journal Neuroscience, 22, 2855-2862.

Meyer-Bernstein, E.L. \& Morin, L.P. (1996). Differential serotonergic innervation of the suprachiasmatic nucleus and the intergeniculate leaflet and its role in circadian rhythm modulation. Journal of
Neuroscience, 16, 2097-2111.

Meyer-Bernstein, E.L., Blanchard, J.H., \& Morin, L.P. (1997). The serotonergic projection from the median raphe nucleus to the suprachiasmatic nucleus modulates activity phase onset, but not other circadian rhythm parameters. Brain Research, 755, 112-120.

Meyer-Bernstein, E.L., \& Morin, L.P. (1999). Electrical stimulation of the median or dorsal raphe nuclei reduces light-induced Fos protein in the suprachiasmatic nucleus and causes circadian activity rhythm phase shifts. Neuroscience, 92, 267-279.

Miller, J.D., Morin, L.P., Schwartz, W.J., \& Moore, R.Y. (1996). New insights into the mammalian circadian clock. Sleep, 19, 641-667.

Mistlberger, R.E. (1994). Circadian food anticipatory activity: formal models and physiological mechanisms. Neuroscience and Biobehavioral Reviews, 18, 171-195.

Mistlberger, R.E., \& Holmes, M.M. (2000). Behavioral feedback regulation of circadian rhythm phase angle in light-dark entrained mice. American Journal of Physiology: Regulatory, Integrative, and Comparative Physiology, 279, R813-R821.

Moga, M.M., \& Moore, R.Y. (1997). Organization of neural inputs to the suprachiasmatic nucleus in the rat. Journal of Comparative Neurology, 389, 508-534.

Moore-Ede, M.C., Sulzman, F.M., \& Fuller, C.A. (1982). The clocks that time us: physiology of the circadian timing system. Cambridge: Harvard University Press.

Moore, R.Y. (1973). Retinohypothalamic projection in mammals: a comparative study. Brain Research, 49, 403-409.

Moore, R.Y. (1993). Organization of the primate circadian system. Journal of Biological Rhythms, 8 Suppl, S3-S9.

Moore, R.Y. (1999). Circadian timing. In: M.J. Zigmond, F.E. Bloom, S.C. Landis, J.L. Roberts \& L.R. Squire (Eds.), Fundamental neuroscience (pp. 1189-1206). San Diego: Academic Press.

Moore, R.Y., \& Eichler, V.B. (1972). Loss of circadian adrenal corticosterone rhythm following suprachiasmatic nucleus lesions in the rat. Brain Research, 42, 201-206.

Moore, R.Y., \& Lenn, N.J. (1972). A retinohypothalamic projection in the rat. Journal Comparative Neurology, 146, 1-14.

Moore, R.Y., Halaris, A.E., \& Jones, B.E. (1978). Serotonin neurons of the midbrain raphe: ascending projections. Journal of Comparative Neurology, 180, 417-438.

Moore, R.Y., Gustafson, E.L., \& Card, J.P. (1984). Identical immunoreactivity of afferents to the rat suprachiasmatic nucleus with antisera against avian pancreatic polypeptide, molluscan cardioexcitatory peptide and neuropeptide Y. Cell and Tissue Research, 236, 41-46.

Moore, R.Y., \& Speh, J.C. (2004). Serotonin innervation of the primate suprachiasmatic nucleus. Brain Research, 1010, 169-173.

Morin, L.P. (1994). The circadian visual system. Brain Research Reviews, 19, 102-127.

Morin, L.P. (2007). SCN organization reconsidered. Journal of Biological Rhythms, 22, 3-13.

Morin, L.P., \& Blanchard, J.H. (2001). Neuromodulator content of hamster intergeniculate leaflet neurons and their projections to the suprachiasmatic nucleus or visual midbrain. Journal of Comparative Neurology, 437, 79-90.

Nascimento, E.S., Jr., Cavalcante, J.S., Cavalcante, J.C., \& Costa, M.S.M.O. (2010). Retinal afferents to the thalamic mediodorsal nucleus in the rock cavy (Kerodon rupestris). Neuroscience Letters, 475, 38-43.

Nascimento, R.B.S., Borda, J.S., Engelberth, R.C.G.J., Medeiros, R.O., Frazão, R., Pinato, L., Pontes, A.L.B.,...Cavalcante, J.S. (2010). The presence of neuronal-specific nuclear protein (NeuN) in the circadian timing system of the capuchin monkey (Cebus paella). Sleep Science, 3, 36-39.

Pasztor, V.M., \& Bush, B.M.H. (1987). Peripheral modulation of mechanosensitivity in primary afferent neurons. Nature, 326, 793-795.

Paxinos, G., \& Watson, C. (1982). The rat brain in stereotaxic coordinates. Sydney: Academic Press.

Pickard, G.E., Weber, E.T., Scott, P.A., Riberdy, A.F. \& Rea, M.A. (1996). $5 \mathrm{HT}_{1 \mathrm{~B}}$ receptor agonists inhibit light-induced phase shifts of behavioral circadian rhythms and expression of the immediateearly gene c-fos in the suprachiasmatic nucleus. Journal of Neuroscience, 16, 8208-8220.

Pickard, G.E., Smith, B.N., Belenky, M., Rea, M.A., Dudek, F.E., \& Sollars, P.J. (1999). 5-HT ${ }_{1 \mathrm{~B}}$ receptor-mediated presynaptic inhibition of retinal input to the suprachiasmatic nucleus. Journal of Neuroscience, 19, 4034-4045.

Pinato, L., Ferreira, Z.S., Markus, R.P., Nogueira, M.I. (2004). 
Bimodal daily variation in the serotonin content in the raphe nuclei of rats. Biological Rhythm Research, 35, 245-257.

Pinato, L., Allemandi, W., Abe, L.K., Frazão, R., Cruz-Rizzolo, R.J., Cavalcante, J.S., Costa, M.S.M.O., \& Nogueira, M.I. (2007). A comparative study of cytoarchitecture and serotonergic afferents in the suprachiasmatic nucleus of primates (Cebus apella and Callithrix jacchus) and rats (Wistar and Long Evans strains). Brain Research, 1149, 101-110.

Portas, C.M., Thakkar, M., Rainnie, D., \& McCarley, R.W. (1996). Microdialysis perfusion of 8-hydroxy-2-(di- $n$-propylamino)tetralin (8-OH-DPAT) in the dorsal raphe nucleus decreases serotonin release and increases rapid eye movement sleep in the freely moving cat. Journal of Neuroscience, 16, 2820-2828.

Prosser, R.A., Miller, J.D., \& Heller, H.C. (1990). A serotonin agonist phase-shifts the circadian clock in the suprachiasmatic nuclei in vitro. Brain Research, 534, 336-339.

Quay, W.B. (1968). Differences in circadian rhythms in 5-hydroxytryptamine according to brain region. American Journal of Physiology, 215, 1448-1453.

Ralph, M.R., Foster, R.G., Davis, F.C., \& Menaker, M. (1990). Transplanted suprachiasmatic nucleus determines circadian period. Science, 247, 975-978.

Ramanathan, C., Nunez, A.A., Martinez, G.S., Schwartz, M.D. \& Smale, L. (2006). Temporal and spatial distribution of immunoreactive PER1 and PER2 proteins in the suprachiasmatic nucleus and peri-suprachiasmatic region of the diurnal grass rat (Arvicanthis niloticus). Brain Research, 1073-1074, 348-358.

Rea, M.A., Glass, J.D., \& Colwell C.S. (1994). Serotonin modulates photic responses in the hamster suprachiasmatic nuclei. Journal of Neuroscience, 14, 3635-3642.

Rea, M.A., Barrera, J., Glass, J.D., \& Gannon, R.L. (1995). Serotonergic potentiation of photic phase shifts of the circadian activity rhythm. Neuroreport, 6, 1417-1420.

Ribak, C.E., \& Peters, A. (1975). An autoradiographic study of the projections from the lateral geniculate body of the rat. Brain Research, 92, 341-368.

Rotenberg, L., Marques, N., \& Menna-Barreto L. (2003). História e perspectivas da cronobiologia. In: N. Marques \& L. MennaBarreto, (Eds.), Cronobiologia: princípios e aplicações (pp. 3153). São Paulo: Editora da Universidade de São Paulo.

Rusak, B., \& Zucker, I. (1979). Neural regulation of circadian rhythms. Physiological Reviews, 59, 449-526.

Sakaguchi, T., \& Bray, G.A. (1989). Effect of norepinephrine, serotonin and tryptophan on the firing rate of sympathetic nerves. Brain Research, 492, 271-280.

Scheurink, A.J., Leuvenink, H., \& Steffens, A.B. (1993). Metabolic and hormonal responses to hypothalamic administration of norfenfluramine in rats. Physiology and Behavior, 53, 889-898.

Schwartz, W.J. (1991). SCN metabolic activity in vitro. In: D.C. Klein, R.Y. Moore \& S.M. Reppert (Eds.), Suprachiasmatic nucleus: the mind's clock (pp. 144-156). Oxford: Oxford University Press.

Sclafani, A., \& Aravich, P.F. (1983). Macronutrient self-selection in three forms of hypothalamic obesity. American Journal of Physiology, 244, R686-R694.

Selim, M., Glass, J.D., Hauser, U.E., \& Rea, M.A. (1993). Serotonergic inhibition of light-induced fos protein expression and extracellular glutamate in the suprachiasmatic nuclei. Brain Research, 621, 181-188.

Shioiri, T., Takahashi, K., Yamada, N., \& Takahashi, S. (1991). Motor activity correlates negatively with free-running period, while positively with serotonin contents in $\mathrm{SCN}$ in free-running rats. Physiology and Behavior, 49, 779-786.

Smale, L., \& Boverhof, J. (1999). The suprachiasmatic nucleus and the intergeniculate leaflet of Arvicanthis niloticus, a diurnal murid rodent from East Africa. Journal of Comparative Neurology, 403, 190-208.

Sollars, P.J., Simpson, A.M., Ogilvie, M.D., \& Pickard, G.E. (2006). Light-induced Fos expression is attenuated in the suprachiasmatic nucleus of serotonin 1B receptor knockout mice. Neuroscience Letters, 401, 209-213.

Stephan, F.K., \& Zucker, I. (1972). Circadian rhythms in drinking behavior and locomotor activity of rats are eliminated by hypothalamic lesions. Proceedings of the National Academy of Sciences of the United States of America, 69, 1583-1586.

Stokkan, K.A., Yamazaki, S., Tei, H., Sakaki, Y., \& Menaker, M. (2001). Entrainment of the circadian clock in the liver by feeding. Science, 291, 490-493.
Swanson, L.W., Cowan, W.M., \& Jones, E.G. (1974). An autoradiographic study of the efferent connections of the ventral geniculate nucleus in the albino rat and the cat. Journal of Comparative Neurology, 156, 143-163.

Taber, E. (1961). The cytoarchitecture of the brain stem of the cat: I. Brain stem nuclei of cat. Journal of Comparative Neurology, 116, 27-69.

Taber, E., Brodal, A., \& Walberg, F. (1960). The raphe nuclei of the brain stem in the cat: I. Normal topography and general discussion. Journal of Comparative Neurology, 114, 161-187.

Takase, L.F., Barone, J.R., \& Nogueira, M.I. (2000). Involvement of the caudal raphe nuclei in the feeding behavior of rats. Brazilian Journal of Medical and Biological Research, 33, 223-228.

Tang-Christensen, M., Havel, P.J., Jacobs, R.R., Larsen, P.J., \& Cameron, J.L. (1999). Central administration of leptin inhibits food intake and activates the sympathetic nervous system in rhesus macaques. Journal of Clinical Endocrinology and Metabolism, 84, 711-717.

Tominaga, K., Shibata, S., Ueki, S., \& Watanabe S. (1992). Effects of $5-\mathrm{HT}_{1 \mathrm{~A}}$ receptor agonists on the circadian rhythm of wheel-running activity in hamsters. European Journal of Pharmacology, 214, 79-84.

Törk, I. (1985). Raphe nuclei and serotonin containing systems. In: G. Paxinos (Ed.), The rat nervous system (pp. 43-78). Sydney: Academic Press.

Törk, I., \& Hornung, J.-P. (1990). Raphe nuclei and the serotoninergic system. In: G. Paxinos (Ed.). The Human Nervous System. (pp. 1001-1002). San Diego: Academic Press.

Trulson, M.E., \& Jacobs, B.L. (1979). Raphe unit activity in freely moving cats: correlation with level of behavioral arousal. Brain Research, 163, 135-150.

Ueda, S., Kawata, M., \& Sano Y. (1983). Identification of serotonin and vasopressin immunoreactivities in the suprachiasmatic nucleus of four mammalian species. Cell Tissues Research, 234, 237-248.

Ukai, H., \& Ueda, H.R. (2010). System biology of mammalian circadian clocks. Annual Review of Physiology, 72, 579-603.

Umbriaco, D., Anctil, M. \& Descarries, L. (1990). Serotoninimmunoreactive neurons in the cnidarian Renilla köllikeri. Journal of Comparative Neurology, 291, 167-178.

Ursin, R. (2002). Serotonin and sleep. Sleep Medicine Reviews, 6, 55-69. van den Pol, A.N., \& Tsujimoto, K.L. (1985). Neurotransmitters of the hypothalamic suprachiasmatic nucleus: immunocytochemical analysis of 25 neuronal antigens. Neuroscience, 15, 1049-1086.

Vansteensel, M.J., Yamazaki, S., Albus, H., Deboer, T., Block, G.D., \& Meijer, J.H. (2003). Dissociation between circadian Per1 and neuronal and behavioral rhythms following a shifted environmental cycle. Current Biology, 13, 1538-1542.

Wang, Z., Toloczko, D., Young, L.J., Moody, K., Newman, J.D., \& Insel, T.R. (1997). Vasopressin in the forebrain of commom marmosets (Callitrhix jacchus): studies with in situ hybridization, immunohistochemistry and receptor autoradiography. Brain Research, 768, 147-156.

Weber, E.T., Gannon, R.L. \& Rea, M.A. (1998). Local administration of serotonin agonists blocks light-induced phase advances of the circadian activity rhythm in the hamster. Journal of Biological Rhythms, 13, 209-218.

Weiss, G.F., Rogacki, N., Fueg, A., Buchen, D., \& Leibowitz, S.F. (1990). Impact of hypothalamic d-norfenfluramine and peripheral d-fenfluramine injection on macronutrient intake in the rat. Brain Research Bulletin, 25, 849-859.

Weiss, G.F., Rogacki, N., Fueg, A., Buchen, D., Suh, J.S., Wong, D.T., \& Leibowitz, S.F. (1991). Effect of hypothalamic and peripheral fluoxetine injection on natural patterns of macronutrient intake in the rat. Psychopharmacology (Berl), 105, 467-476.

Welsh, J.H. (1970). Phylogenetic aspects of the distribution of biogenic amines. In: J.J. Blum (Ed.), Biogenic amines as physiological regulators (pp. 75-94). Englewood Cliffs, N.J.: Prentice-Hall.

Willard, A.L. (1981). Effects of serotonin on the generation of the motor program for swimming by the medicinal leech. Journal of Neuroscience, 1, 936-944

Yannielli, P.C., Cutrera, R.A., Cardinali, D.P., \& Golombek, D.A. (1998). Neonatal clomipramine treatment of Syriam hamsters: effect on the circadian system. European Journal Pharmacology, 349, 143-150.

Yannielli, P.C. \& Harrington, M.E. (2000). Neuropeptide Y applied in vitro can block the phase shifts induced by light in vivo. Neuroreport, 11, 1587-1591. 